\title{
Relationship between Synthesis Conditions and Photocatalytic Activity of Nanocrystalline $\mathrm{TiO}_{2}$
}

\author{
Yosep Han, ${ }^{1}$ Hyung-Seok Kim, ${ }^{2}$ and Hyunjung Kim ${ }^{3}$ \\ ${ }^{1}$ Department of Natural Resource and Environmental Engineering, Hanyang University, 17 Heangang-Dong, Seongdong-gu, \\ Seoul 133-791, Republic of Korea \\ ${ }^{2}$ Mineral Resources Research Division, Korea Institute of Geoscience and Mineral Resources, Daejeon 305-350, Republic of Korea \\ ${ }^{3}$ Department of Mineral Resources and Energy Engineering, Chonbuk National University, 664-14 Duckjin-Dong, Duckjin-gu, Jeonju, \\ Jeonbuk 561-756, Republic of Korea
}

Correspondence should be addressed to Hyunjung Kim, kshjkim@jbnu.ac.kr

Received 25 March 2012; Revised 3 June 2012; Accepted 3 June 2012

Academic Editor: Jiaguo Yu

Copyright (c) 2012 Yosep Han et al. This is an open access article distributed under the Creative Commons Attribution License, which permits unrestricted use, distribution, and reproduction in any medium, provided the original work is properly cited.

The degradation efficiency of methylene blue by $\mathrm{TiO}_{2}$ nanoparticles, which were synthesized under different synthesis conditions (i.e., molar ratio of water and titanium tetraisopropoxide (TTIP), $\mathrm{pH}$, and calcination temperature) in a sol-gel process, was systematically investigated. The results showed that increasing the molar ratio of water and TTIP led to the enhanced photocatalytic activity of $\mathrm{TiO}_{2}$ nanoparticles, which were likely attributed to the increased specific surface area of $\mathrm{TiO}_{2}$ nanoparticles synthesized with high molar ratio. The results were supported by the relative increase in the size of interaggregated pores of the aggregated $\mathrm{TiO}_{2}$ nanoparticles. The best photocatalytic activity of $\mathrm{TiO}_{2}$ nanoparticles was observed at acidic synthesis conditions; however, the results were not consistent with physical properties for the crystallinity and the crystallite size of $\mathrm{TiO}_{2}$ nanoparticles but rather explained by the presence of abundant hydroxyl groups and water molecules existing on the surface of $\mathrm{TiO}_{2}$ under acidic synthesis environments. Furthermore, methylene blue degradation experiments revealed that the photocatalytic activity of $\mathrm{TiO}_{2}$ nanoparticles was maximized at the calcination temperature of $700^{\circ} \mathrm{C}$. The trend was likely due to the combined effect of the anatase crystallinity which showed the highest value at $700^{\circ} \mathrm{C}$ and the crystallite size/specific surface area which did not excessively increase up to $700^{\circ} \mathrm{C}$.

\section{Introduction}

$\mathrm{TiO}_{2}$ is utilized in different environmental applications, such as gas sensors $[1,2]$ and photocatalytic degradation of various contaminants in waste-air and/or wastewater treatment [3-6]. $\mathrm{TiO}_{2}$ usually has two crystalline phases, anatase $\left(E_{g}=\right.$ $3.2 \mathrm{eV})$ and rutile $\left(E_{g}=3.0 \mathrm{eV}\right)$, and the anatase phase frequently exhibits higher photocatalytic activity than the rutile phase [7-10]. The most popular commercial $\mathrm{TiO}_{2}$ named by Degussa P25, containing around 70\% anatase and $30 \%$ rutile, is known to possess excellent photocatalytic activity [7, 11]. The high activity of Degussa P25 was mainly attributed to the mixed phase composition and the high anatase crystallinity, which would favor photo-induced charge separation as well as large specific surface area.

In addition to the phase composition, the specific surface area and anatase crystallinity are important factors influencing the photocatalytic performance of $\mathrm{TiO}_{2}$. Photocatalytic reactions using $\mathrm{TiO}_{2}$ particles degrade pollutants by interaction with contaminants on the surfaces of the particles. Therefore, as the specific surface area of the particles increases, the contact area with contaminants increases and consequently the degradation efficiency increases. Also, increasing anatase crystallinity results in the decrease in the recombination rate of the electrons and holes so that the photocatalytic efficiency improves $[7,12,13]$.

Generally, a sol-gel method based on the hydrolysis of titanium alkoxide is widely used to synthesize $\mathrm{TiO}_{2}$ nanoparticles [14]. However, this method encounters some problems, such as weak anatase crystallinity and poor monodispersity. In addition, nanocrystalline $\mathrm{TiO}_{2}$ prepared by the sol-gel method undergoes both phase transformation and crystallite size growth even at relative low temperature [15]. To apply $\mathrm{TiO}_{2}$ particles synthesized from the sol-gel process 
as photocatalytic catalysts, it is important to maintain high anatase crystallinity [16]. Previous study reported that high degree of anatase crystallinity can be achieved without high temperature calcination when $\mathrm{TiO}_{2}$ particles were synthesized at low temperature due to fast hydrolysis and slow condensation [17]. In addition, many studies regarding the evaluation of the photocatalytic activity of $\mathrm{TiO}_{2}$ nanoparticles have been conducted (e.g., [12, 18-20]); however, few focused on the correlation between parameters used in the synthesis process of $\mathrm{TiO}_{2}$ nanoparticles and their photocatalytic activity $[18,21]$.

Therefore, this study was designed to investigate the effect of synthesis conditions (i.e., molar ratio (water: titanium tetraisopropoxide (TTIP)), $\mathrm{pH}$, and calcination temperature) on physicochemical surface characteristics (e.g., specific surface area, pore volume, crystallinity, and crystallite size of synthesized $\mathrm{TiO}_{2}$, and functional groups onto the surface of $\mathrm{TiO}_{2}$ nanoparticles) as well as initial photocatalytic activity of $\mathrm{TiO}_{2}$ nanoparticles for the samples synthesized under different conditions.

\section{Materials and Methods}

2.1. Preparation of $\mathrm{TiO}_{2}$ Nanoparticles. The nanocrystalline $\mathrm{TiO}_{2}$ particles were prepared via a sol-gel process using TTIP (Sigma-Aldrich, St. Louis, MO) and deionized water (Milli-Q, Millipore, Bedford, MA) as the starting materials. TTIP was dissolved in anhydrous alcohol (Sigma-Aldrich). The molar composition of the prepared solution was $1: 30$ (TTIP:alcohol). The controlled solution was then added dropwise to a known amount of deionized water. The molar ratios of deionized water and TTIP were set to $2,5,10,20$, and 50. In order to investigate the effect of the synthesis $\mathrm{pH}$ value on the phase transformation (anatase to rutile) and crystallite size, hydrochloric acid or aqueous ammonia was dropped into the mixed solution to yield gels with different $\mathrm{pH}$ values. The hydrolysis reaction was maintained under agitation condition at a reaction temperature of $20^{\circ} \mathrm{C}$ for $24 \mathrm{~h}$. Under these conditions, the precipitation took place rapidly. The as-synthesized samples were recovered by centrifugation (MF80, Hanil, Seoul, Korea), rinsed with deionized water and alcohol, and dried at $80^{\circ} \mathrm{C}$ for $24 \mathrm{~h}$. The synthesized $\mathrm{TiO}_{2}$ nanoparticles were calcined with a heat rising rate of $3^{\circ} \mathrm{C} \min ^{-1}$ and a keeping time of $2 \mathrm{~h}$. The temperature range investigated herein was $400-1000^{\circ} \mathrm{C}$.

2.2. Photocatalytic Activity. A quartz glass reactor with a lamp immersed in the inner part of the reactor was used for all the photocatalytic experiments. The batch reactor was filled with $250 \mathrm{~mL}$ of an aqueous dispersion in which the concentrations of $\mathrm{TiO}_{2}$ and methylene blue were $0.5 \mathrm{~g} \mathrm{~L}^{-1}$ and $10 \mathrm{mg} \mathrm{L}^{-1}$, respectively. Photocatalytic activity of the synthesized $\mathrm{TiO}_{2}$ was compared with that of $\mathrm{P} 25$, and the solution without $\mathrm{TiO}_{2}$ catalysts was set as the point of comparison to consider the effect of pure degradation by the light source. In order to quantitatively compare the relative photocatalytic activity of $\mathrm{TiO}_{2}$ samples, first-order reaction rate constant $(k)$ for each sample was obtained from the degradation data with irradiation time [22]. Prior to the emission of UV light, the reactor containing $\mathrm{TiO}_{2}$ particles and methylene blue was left for $30 \mathrm{~min}$ in a dark room to allow the adsorption/desorption equilibrium condition to be met [23]. A $120 \mathrm{~W}$ high pressure mercury lamp (Daesung Lamp Co., Republic of Korea) with a wavelength of $320-400 \mathrm{~nm}$ (a maximum emission at about $350 \mathrm{~nm}$ ) and a light intensity of $12.0 \mathrm{MW} \mathrm{cm}^{-2}$ at $350 \mathrm{~nm}$ was used as UV light sources. After photocatalytic reaction, the samples were immediately centrifuged and the quantitative determination of methylene blue was performed by a UV-vis spectrophotometer (CE 3041, Cecil, UK).

2.3. Characterization of $\mathrm{TiO}_{2}$ Nanoparticles. X-ray diffraction (XRD) studies were carried out by using an Xray diffractometer (Bruker D8 HRXRD, Germany). X-ray diffraction patterns were recorded using $\mathrm{CuK} \alpha$ radiation in the step-scan mode with a $2 \theta$ range of $10^{\circ}$ to $80^{\circ}$. The scanning was performed in steps of $0.015^{\circ} 2 \theta$ with an interval of $10 \mathrm{sec}$. The crystallite size and the relative amounts of the anatase and rutile phase were calculated from the (101) reflection of anatase and the (110) reflection of rutile. The crystallite size of anatase and rutile phase was calculated using the Scherrer's equation [22]:

$$
t=\frac{k \lambda}{s \cos \theta}
$$

where $t$ is the crystallite size, $\lambda$ is the wavelength of the X-ray radiation $(\mathrm{CuK} \alpha=0.15406 \mathrm{~nm}, 40 \mathrm{kV}, 40 \mathrm{mV}), k$ is a constant that was set to $0.94, \theta$ is the diffraction angle, and $s$ is the line width at half maximum height. The weight fractions of anatase present in $\mathrm{TiO}_{2}$ nanoparticles synthesized under various conditions were calculated using the equation given below [24]:

$$
\chi=\frac{1}{1+1.26\left(I_{\mathrm{A}} / I_{\mathrm{R}}\right)},
$$

where $\chi$ is the weight fraction of the anatase phase, $I_{\mathrm{A}}$ is the diffraction peak intensity of the anatase (101) phase, and $I_{R}$ is the diffraction peak intensity of the rutile (110) phase. Nitrogen adsorption to synthesized nanoparticles was measured using an AutoSorb-1 system from Quantachrome Instruments (Syosset, NY). The samples were evacuated prior to each measurement at $300^{\circ} \mathrm{C}$ in a high vacuum for $6 \mathrm{~h}$. Specific surface area, pore size distributions, and pore volume were calculated from nitrogen adsorption isotherms. Specific surface area $\left(S_{\mathrm{BET}}\right)$ was calculated from the data obtained from partial relative pressure ranged between 0.05 and 0.25 using the Brunauer-Emmett-Teller (BET) method $[25,26]$. Pore volume and pore size distributions were determined from the amount of nitrogen adsorbed at a relative pressure of 0.99 and by the Barrett-JoynerHalenda (BJH) method [27, 28]. The morphology of prepared $\mathrm{TiO}_{2}$ nanoparticles was determined by transmission electron microscopy (FE-TEM, JEM-2100F, JEOL, Japan). The accelerating voltage of the electron beam was $220 \mathrm{kV}$. The samples for TEM measurements were suspended in ethanol and dropped onto holey carbon films supported 
TABLE 1: Results for the photodecomposition of methylene blue using the nanocrystalline $\mathrm{TiO}_{2}$ powders synthesized at various conditions.

\begin{tabular}{|c|c|c|c|c|}
\hline & Sample & Adsorption amount ${ }^{\mathrm{a}}\left(\mathrm{mg} \mathrm{g}^{-1}\right)$ & First-order reaction rate constant $(k)^{\mathrm{b}}\left(\mathrm{h}^{-1}\right)$ & Decomposition ratio $^{c}(-)$ \\
\hline & $\mathrm{P} 25$ & 0.80 & 0.536 & 0.460 \\
\hline \multirow{5}{*}{ Molar ratio ${ }^{\mathrm{d}}(-)$} & 2 & 0.41 & 0.295 & 0.263 \\
\hline & 5 & 1.10 & 0.690 & 0.538 \\
\hline & 10 & 1.21 & 0.786 & 0.621 \\
\hline & 20 & 1.68 & 0.846 & 0.640 \\
\hline & 50 & 2.02 & 0.873 & 0.657 \\
\hline \multirow{5}{*}{$\mathrm{pH}^{\mathrm{e}}$} & 2.5 & 1.03 & 0.894 & 0.658 \\
\hline & 4 & 0.92 & 0.864 & 0.641 \\
\hline & 7 & 1.10 & 0.690 & 0.538 \\
\hline & 9 & 0.85 & 0.588 & 0.480 \\
\hline & 11 & 1.46 & 0.551 & 0.440 \\
\hline \multirow{7}{*}{ Temperature ${ }^{\mathrm{f}}\left({ }^{\circ} \mathrm{C}\right)$} & 400 & 2.37 & 0.516 & 0.395 \\
\hline & 500 & 1.21 & 0.431 & 0.357 \\
\hline & 600 & 1.10 & 0.690 & 0.538 \\
\hline & 700 & 0.98 & 0.871 & 0.614 \\
\hline & 800 & 0.22 & 0.701 & 0.515 \\
\hline & 900 & 0.20 & 0.468 & 0.376 \\
\hline & 1000 & 0.20 & 0.511 & 0.385 \\
\hline
\end{tabular}

${ }^{\mathrm{a}}$ Amount of methylene blue adsorbed for first $30 \mathrm{~min}$ (refer to the adsorption zone in Figures 1, 5, and 8).

${ }^{b}$ Value determined by fitting the data for the photolysis zone in Figures 1, 5, and 8 to first-order reaction.

${ }^{\mathrm{c}}$ Ratio between degraded and initial amounts.

${ }^{\mathrm{d}}$ Other synthesis conditions are as follows: $\mathrm{pH}=7$ and calcination temperature $=600{ }^{\circ} \mathrm{C}$.

${ }^{\mathrm{e}}$ Other synthesis conditions are as follows: molar ratio $=5$ and calcination temperature $=600{ }^{\circ} \mathrm{C}$.

${ }^{\mathrm{f}}$ Other synthesis conditions are as follows: molar ratio $=5$ and $\mathrm{pH}=7$.

TABLE 2: Physicochemical properties of the $\mathrm{TiO}_{2}$ nanoparticles synthesized with different molar ratios of water and TTIP. The TiO ${ }_{2}$ synthesis was carried out at $\mathrm{pH} 7$ and at a calcination temperature of $600^{\circ} \mathrm{C}$.

\begin{tabular}{|c|c|c|c|c|}
\hline Molar ratio (-) & Phase content $^{\mathrm{a}}$ & $S_{\mathrm{BET}}^{\mathrm{b}}\left(\mathrm{m}^{2} \mathrm{~g}^{-1}\right)$ & Pore volume ${ }^{\mathrm{b}}\left(\mathrm{mm}^{3} \mathrm{~g}^{-1}\right)$ & Crystalline size $^{\mathrm{c}}(\mathrm{nm})$ \\
\hline 2 & (A): 100 & 29.6 & 38 & 18.2 \\
\hline 5 & (A): 100 & 38.2 & 69 & 18.0 \\
\hline 10 & (A): 100 & 44.0 & 58 & 19.2 \\
\hline 20 & (A): 100 & 51.0 & 92 & 18.5 \\
\hline \multirow[t]{2}{*}{50} & (A): 82.5 & 63.9 & 110 & (A): 18.5 \\
\hline & (R): 17.5 & & & (R): 19.3 \\
\hline
\end{tabular}

${ }^{\mathrm{a}} \mathrm{A}$ and $\mathrm{R}$ represent anatase and rutile, respectively.

${ }^{b}$ Value calculated from nitrogen adsorption isotherm.

'Value calculated using the Scherrer's equation [22].

on $\mathrm{Cu}$ grids for imaging. Surface functional groups were examined using a Fourier transform infrared spectrometer (FT-IR, FT/IR-4100, JASCO, Japan) in the range of 650$4000 \mathrm{~cm}^{-1}$.

\section{Results and Discussion}

3.1. Effect of Molar Ratio of Water and TTIP on Photocatalytic Activity of $\mathrm{TiO}_{2}$. Figure 1 and Table 1 represent the initial adsorption amount of methylene blue and the photocatalytic activity of synthesized $\mathrm{TiO}_{2}$ according to the amount of water added during $\mathrm{TiO}_{2}$ synthesis process. The $\mathrm{pH}$ of the water added was 7, and the calcination temperature was set to $600^{\circ} \mathrm{C}$. The adsorption amount of methylene blue increased with increasing molar ratio, which is consistent with increasing specific surface area of $\mathrm{TiO}_{2}$ samples with increasing molar ratio (Table 2). For the photocatalytic activity of $\mathrm{TiO}_{2}$ samples, greater degree of degradation for methylene blue was observed for higher water concentration ranges, and particularly the enhancement of photocatalytic activity was pronounced when the molar ratio was greater than 20 (i.e., $k=0.873$ and $0.846 \mathrm{~h}^{-1}$ for the samples with molar ratio of 50 and 20, resp.). Moreover, except for the $\mathrm{TiO}_{2}$ sample produced with a molar ratio of 2 , all samples were found to have higher activity than P25.

Figure 2 and Table 2 show an XRD pattern of the synthesized $\mathrm{TiO}_{2}$ prepared with different molar ratios of water and TTIP. The XRD peaks at $2 \theta=25.28$ and $2 \theta=$ 27.40 are known to be the characteristic peaks of anatase (101) and rutile (110) crystal phases, respectively [5]. An anatase (101) phase started to appear from the sample with a molar ratio of 2 , and the phase was maintained until the 


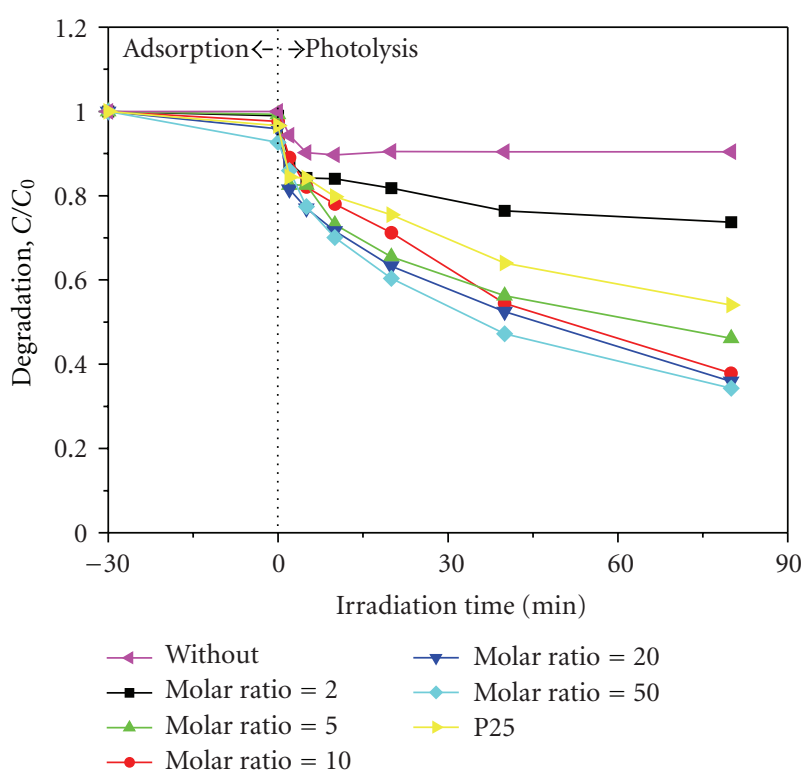

Figure 1: Photocatalytic degradation of methylene blue by $\mathrm{TiO}_{2}$ nanoparticles synthesized with different molar ratios of water and TTIP. The $\mathrm{TiO}_{2}$ synthesis was carried out at $\mathrm{pH} 7$ and at a calcination temperature of $600^{\circ} \mathrm{C}$. The results from the experiments with P25 and without $\mathrm{TiO}_{2}$ nanoparticles were also presented for comparison purpose.

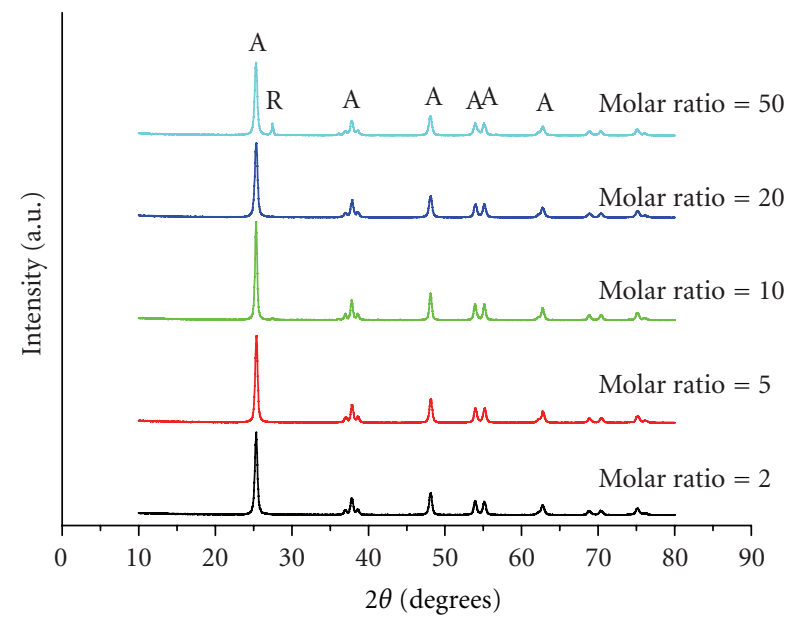

FIgURE 2: XRD patterns of $\mathrm{TiO}_{2}$ nanoparticles synthesized with different molar ratios of water and TTIP. The $\mathrm{TiO}_{2}$ synthesis was carried out at $\mathrm{pH} 7$ and at a calcination temperature of $600^{\circ} \mathrm{C}$. A and $\mathrm{R}$ represent anatase and rutile, respectively.

molar ratio was 20. The existence of the anatase phase over the broad range of molar ratio is likely due to the calcination temperature (i.e., $600^{\circ} \mathrm{C}$ ) [15]. However, the $\mathrm{TiO}_{2}$ samples with the molar ratio of 50 exhibited a rutile peak, indicating that phase transition from anatase to rutile started to occur at this point (Figure 2 and Table 2). This suggests that excessive water additive caused a phase transition for the synthesized $\mathrm{TiO}_{2}$ as observed from a previous study [29]. However, regardless of the molar ratio, the crystallite size for the synthesized $\mathrm{TiO}_{2}$ samples was consistently measured to be about 18-19 nm (Table 2), indicating that the crystallite size of the synthesized $\mathrm{TiO}_{2}$ was not significantly affected by the water amount added.

In order to understand the effect of molar ratio of water and TTIP on the photocatalytic activity of synthesized $\mathrm{TiO}_{2}$, physical properties (i.e., pore volume and specific surface area) of the synthesized $\mathrm{TiO}_{2}$ particles were evaluated, and the results are presented in Table 2 . The results showed that the specific surface area and pore volume increased with increasing molar ratio (i.e., increasing water amount). Particularly, for the $\mathrm{TiO}_{2}$ sample synthesized with the largest molar ratio of 50, the specific surface area and pore volume were determined to be $63.9 \mathrm{~m}^{2} \mathrm{~g}^{-1}$ and $110 \mathrm{~mm}^{3} \mathrm{~g}^{-1}$, respectively. Figure 3 shows TEM images to show the morphology of the synthesized $\mathrm{TiO}_{2}$ nanoparticles for the highest and lowest molar ratio (molar ratio $=50$ for Figures $3(\mathrm{a})$ and $3(\mathrm{~b}$ ) and molar ratio $=2$ for Figures $3(\mathrm{c})$ and $3(\mathrm{~d})$ ). No difference in the particle shape was observed for the two samples with respect to the $\mathrm{TiO}_{2}$ synthesis conditions. In addition, the synthesized particles were found to be aggregated and form many inter-aggregated pores. Hence, it is reasonable to hypothesize that the greater specific surface area and pore volume for the $\mathrm{TiO}_{2}$ nanoparticles with higher molar ratio are likely due to the formation of more pores by the cohesion between aggregated particles. This hypothesis is supported by the result for the distribution of the pore sizes (Figure 4) for the synthesized $\mathrm{TiO}_{2}$ samples according to the amount of water added. When a relatively small amount of water was added (molar ratio $\leq 10$ ), the $\mathrm{TiO}_{2}$ nanoparticles were found to mostly possess pores with the size of $2-5 \mathrm{~nm}$; however, when molar ratio was greater than 20, the extra pores greater than $5 \mathrm{~nm}$ were observed to form. Moreover, for the samples with molar ratio of 20 and 50, it was observed that large quantity of extra pores with the size of 10 and $8 \mathrm{~nm}$, respectively, formed as compared to those with low molar ratio. This result further confirmed that higher dosage of water led to the greater formation of the inter-aggregated pores due to the cohesion between $\mathrm{TiO}_{2}$ nanoparticles. Consequently, larger specific surface area and higher pore volume for the synthesized $\mathrm{TiO}_{2}$ nanoparticles with high molar ratio are thought to lead to better degradation efficiency for methylene blue [30-32].

3.2. Effect of Synthesis $p H$ on Photocatalytic Activity of $\mathrm{TiO}_{2}$. In order to investigate the effect of synthesis $\mathrm{pH}$ on photolysis efficiency of $\mathrm{TiO}_{2}$ nanoparticles, the degradation rate of methylene blue by $\mathrm{TiO}_{2}$ nanoparticles, which was synthesized under various $\mathrm{pH}$ levels of water, was examined and the results are presented in Figure 5 and Table 1. The amount of water added as a hydrolysis reagent was $5 \mathrm{~mol}$ (i.e., molar ratio of water and TTIP $=5$ ), and the calcination temperature was fixed to $600^{\circ} \mathrm{C}$. Similar with the results for molar ratio, the adsorption amount of methylene blue was greater than for the samples with high specific surface area (Tables 1 and 3).

Overall, the samples synthesized at low $\mathrm{pH}$ conditions exhibited greater photocatalytic activity than P25 (i.e., $k=$ $0.536 \mathrm{~h}^{-1}$ for $\mathrm{P} 25$ and $k \geq 0.551 \mathrm{~h}^{-1}$ for all samples 


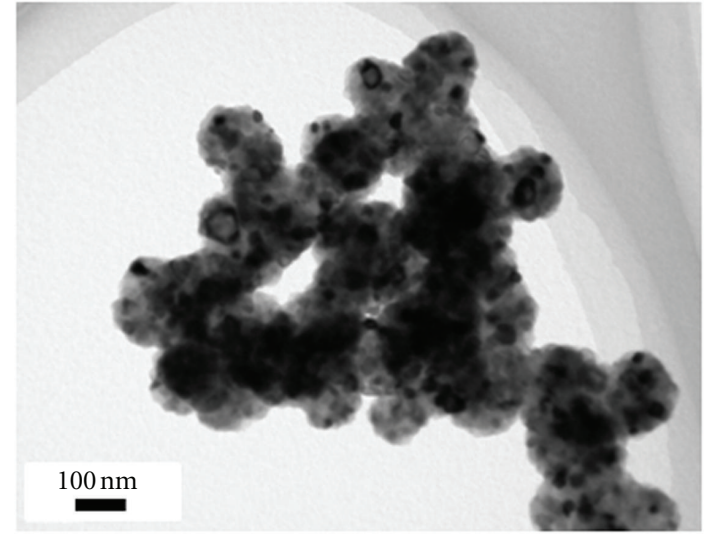

(a)

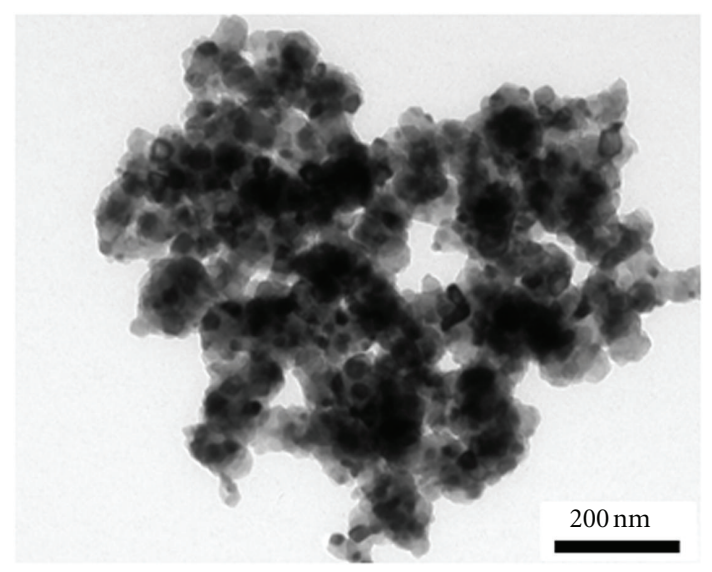

(c)

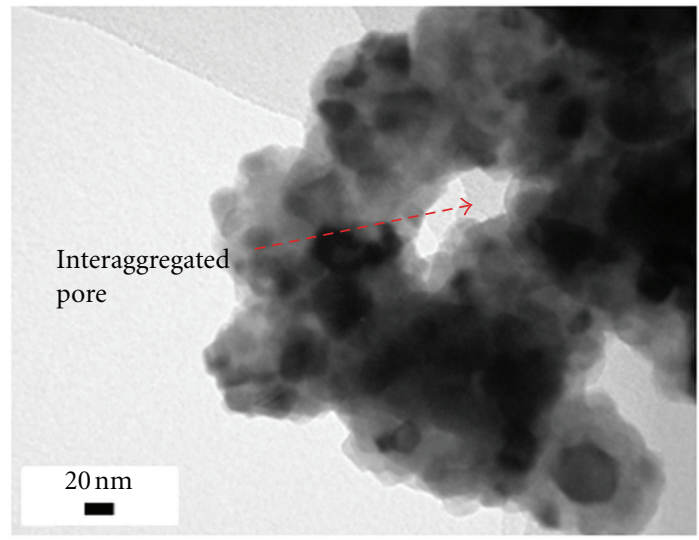

(b)

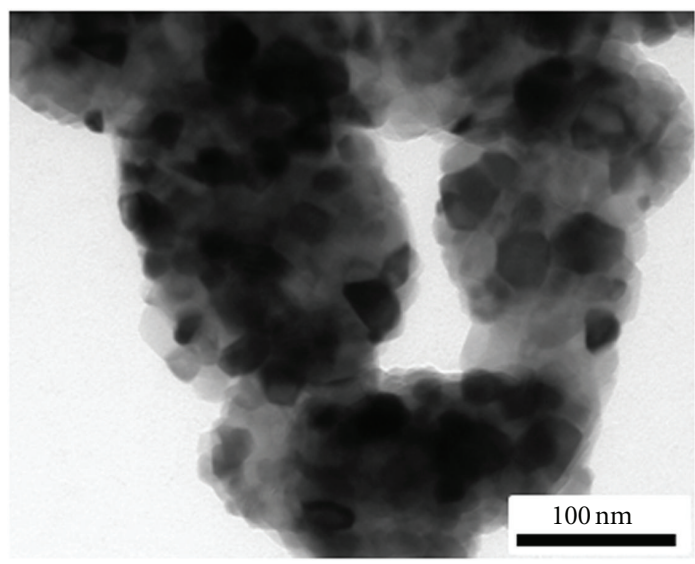

(d)

Figure 3: TEM images of $\mathrm{TiO}_{2}$ nanoparticles synthesized with different molar ratios of water and TTIP: (a and b) 50 and (c and d) 2. The $\mathrm{TiO}_{2}$ synthesis was carried out at $\mathrm{pH} 7$ and at a calcination temperature of $600^{\circ} \mathrm{C}$.

TABle 3: Physicochemical properties of the $\mathrm{TiO}_{2}$ nanoparticles synthesized with different $\mathrm{pH}$ conditions. The $\mathrm{TiO}_{2}$ synthesis was carried out with a molar ratio (water and TTIP) of 5 and at a calcination temperature of $600^{\circ} \mathrm{C}$.

\begin{tabular}{lcccc}
\hline $\mathrm{pH}$ & Phase content $\mathrm{t}^{\mathrm{a}}$ & S $_{\mathrm{BET}}{ }^{\mathrm{b}}\left(\mathrm{m}^{2} \mathrm{~g}^{-1}\right)$ & Pore volume $^{\mathrm{b}}\left(\mathrm{mm}^{3} \mathrm{~g}^{-1}\right)$ & Crystalline size $^{\mathrm{c}}(\mathrm{nm})$ \\
\hline 2.5 & (A): 100 & 32.2 & 45 & 13.2 \\
4 & (A): 100 & 25.5 & 33 & 17.0 \\
7 & $(\mathrm{~A}): 100$ & 38.2 & 69 & 18.0 \\
9 & $(\mathrm{~A}): 33.2$ & 16.8 & 28 & $(\mathrm{~A}): 21.4$ \\
& $(\mathrm{R}): 66.8$ & & & $(\mathrm{R}): 23.0$ \\
11 & (A): 10.3 & 46.3 & 58 & $(\mathrm{~A}): 22.1$ \\
& (R): 89.7 & & & $(\mathrm{R}): 28.5$ \\
\hline
\end{tabular}

\footnotetext{
${ }^{\mathrm{a}} \mathrm{A}$ and $\mathrm{R}$ represent anatase and rutile, respectively.

bValue calculated from nitrogen adsorption isotherm.

${ }^{c}$ Value calculated using the Scherrer's equation [22].
}

synthesized) (Table 1). Especially, the $\mathrm{TiO}_{2}$ sample synthesized at $\mathrm{pH} 2.5$ showed the best photocatalytic activity (i.e., $k=0.894 \mathrm{~h}^{-1}$ ). The above results indicate that photocatalytic activity of synthesized $\mathrm{TiO}_{2}$ nanoparticles is a function of the synthesis $\mathrm{pH}$ of water which was used as a hydrolysis reagent [33].
Figure 6 and Table 3 illustrate XRD patterns of $\mathrm{TiO}_{2}$ samples synthesized under different $\mathrm{pH}$ conditions. Anatase phase was observed when hydrolysis reagent was acidic $(\mathrm{pH} \leq 7)$, but as $\mathrm{pH}$ increased, crystalline phase of synthesized $\mathrm{TiO}_{2}$ showed a transition to the rutile phase $(\mathrm{pH} \geq 9)$, which is consistent with the results observed from a previous 


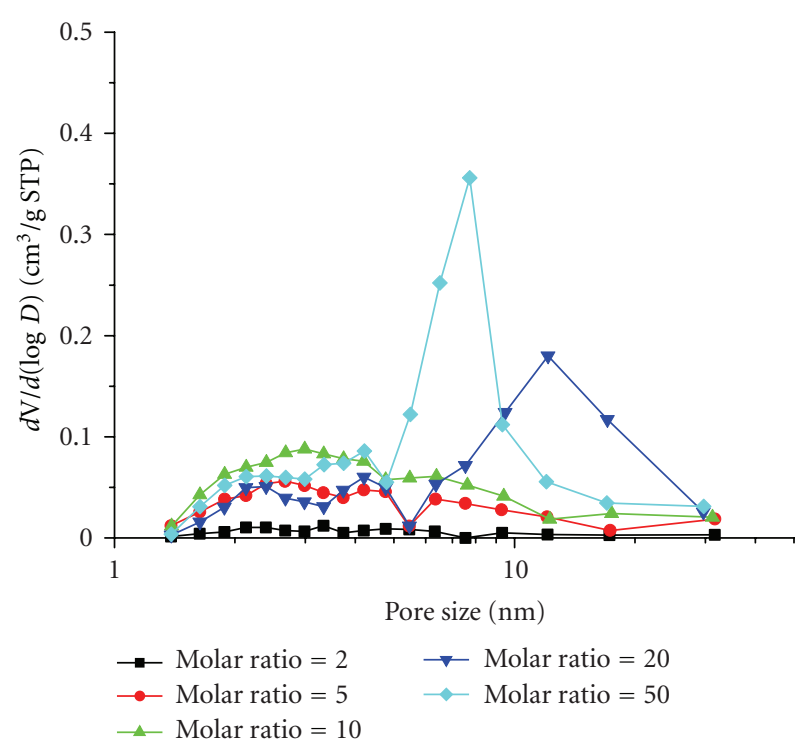

Figure 4: $\mathrm{BJH}$ pore size distributions for $\mathrm{TiO}_{2}$ nanoparticles synthesized with different molar ratios of water and TTIP. The $\mathrm{TiO}_{2}$ synthesis was carried out at $\mathrm{pH} 7$ and at a calcination temperature of $600^{\circ} \mathrm{C}$.

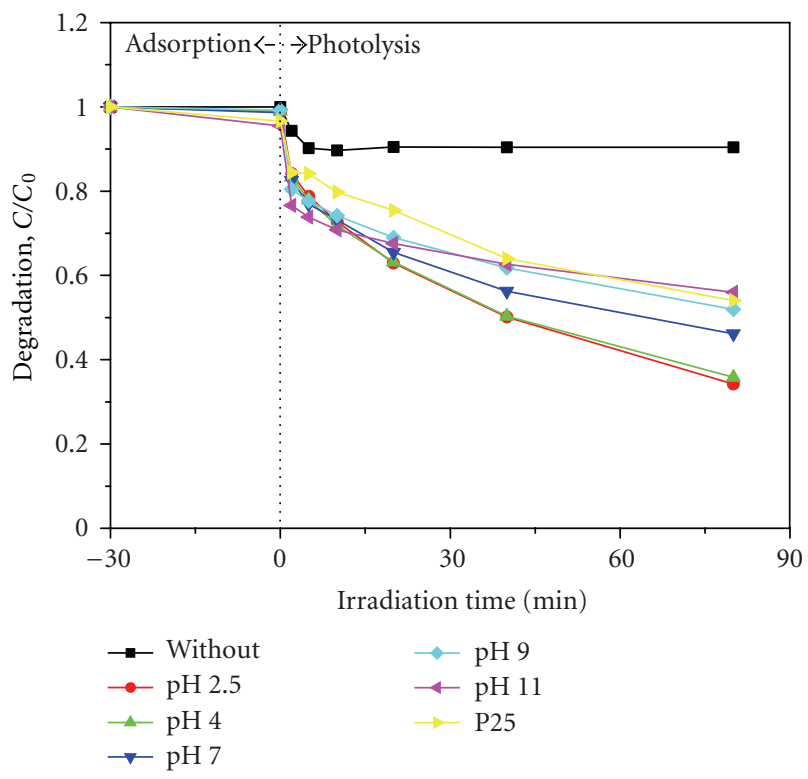

FIgURe 5: Photocatalytic degradation of methylene blue by $\mathrm{TiO}_{2}$ nanoparticles synthesized at different $\mathrm{pH}$ conditions. The $\mathrm{TiO}_{2}$ synthesis was carried out with a molar ratio (water and TTIP) of 5 and a calcination temperature of $600^{\circ} \mathrm{C}$. The results from the experiments with $\mathrm{P} 25$ and without $\mathrm{TiO}_{2}$ nanoparticles were also presented for comparison purpose.

study [29]. Specifically, an anatase phase was observed at $\mathrm{pH} 2.5$, and the anatase peak increased up to $\mathrm{pH} 7$ with maximum peak value (Figure 5); however, rutile peak started to be observed at $\mathrm{pH} 9$, and the peak was more pronounced for the sample at $\mathrm{pH} 11$.

The sizes of $\mathrm{TiO}_{2}$ synthesized under different $\mathrm{pH}$ were observed to increase in accordance with increasing $\mathrm{pH}$

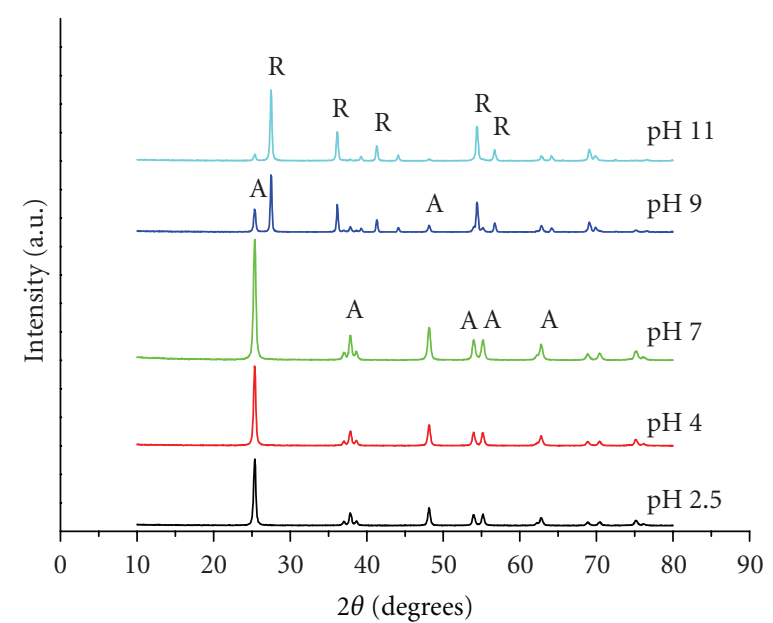

FIgURE 6: XRD patterns of $\mathrm{TiO}_{2}$ nanoparticles synthesized at different $\mathrm{pH}$ conditions. The $\mathrm{TiO}_{2}$ synthesis was carried out with a molar ratio (water and TTIP) of 5 and a calcination temperature of $600^{\circ} \mathrm{C}$. A and $\mathrm{R}$ represent anatase and rutile, respectively.

(Table 3). It has been known that phase transition of $\mathrm{TiO}_{2}$ led to the increase in crystallite size [34], which is consistent with our results. Specifically, as the synthesis $\mathrm{pH}$ increased, phase transition occurred in synthesized $\mathrm{TiO}_{2}$ nanoparticles, and eventually crystallite size slightly increased. The results from both crystalline phase and crystallite size for synthesized $\mathrm{TiO}_{2}$, suggest that photocatalytic activity of $\mathrm{TiO}_{2}$ is expected to be maximized at $\mathrm{pH} 7$ since anatase crystallinity was greatest at $\mathrm{pH} 7$ with similar crystallite size as compared to that at other $\mathrm{pH}$ conditions [35-37]. However, samples synthesized at acidic conditions (i.e., $\mathrm{pH} 2$ and 4) showed the best photocatalytic activity, implying that it was not enough to explain the result of photocatalytic performance only by the properties of crystallinity and crystallite size of $\mathrm{TiO}_{2}$ nanoparticles.

Previously, some studies reported that the more $\mathrm{OH}$ groups existed on the surface of $\mathrm{TiO}_{2}$, the greater photocatalytic activity appeared $[38,39]$. Hence, the degree of $\mathrm{OH}$ groups existing on the surface of synthesized $\mathrm{TiO}_{2}$ samples was also investigated using FT-IR spectra in this study. The FT-IR spectra of the nanocrystallite $\mathrm{TiO}_{2}$ powders are shown in Figure 7. The broad peak appearing between 3200 and $3600 \mathrm{~cm}^{-1}$ is assigned to the stretching vibrations of the $\mathrm{OH}$ groups [40]. The peaks in the range of $1620-1630 \mathrm{~cm}^{-1}$ are attributed to the bending vibrations of the surface-adsorbed water molecules [41]. The main peak appearing in the range $650-700 \mathrm{~cm}^{-1}$ corresponds to Ti-O and Ti-O-Ti stretching vibrations [41, 42]. The FT-IR spectra of all samples showed the characteristic peaks of $\mathrm{Ti}-\mathrm{O}$ and $\mathrm{Ti}-\mathrm{O}-\mathrm{Ti}$ stretching vibrations in the range of $650-700 \mathrm{~cm}^{-1}$. However, the amount of adsorbed water molecules and hydroxyl groups was different between the samples synthesized at different $\mathrm{pH}$ conditions as evidenced by the intensity of the bands corresponding to the bending vibrations of surface-adsorbed molecules $\left(1620-1630 \mathrm{~cm}^{-1}\right)$ and the stretching vibrations of the hydroxyl groups $\left(3200-3600 \mathrm{~cm}^{-1}\right)$. Relatively huge difference in the FT-IR spectra was observed in the intensity 


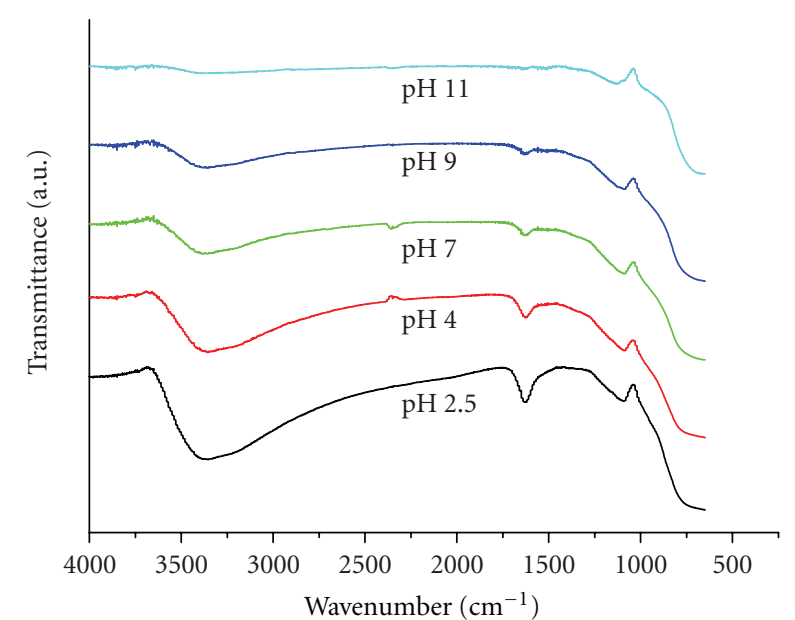

Figure 7: FT-IR spectra of $\mathrm{TiO}_{2}$ nanoparticles synthesized at different $\mathrm{pH}$ conditions. The $\mathrm{TiO}_{2}$ synthesis was carried out with a molar ratio (water and TTIP) of 5 and a calcination temperature of $600^{\circ} \mathrm{C}$.

of the peak appearing between 3200 and $3600 \mathrm{~cm}^{-1}$ assigned to the stretching vibrations of the hydroxyl group. Additionally, the sample synthesized under more acidic conditions was observed to possess larger amount of adsorbed water. The FT-IR results indicate that the amount of adsorbed water molecules and hydroxyl groups on the surface of $\mathrm{TiO}_{2}$ nanoparticles is closely related to their photocatalytic activity. It has been previously reported that, during a solgel process under low $\mathrm{pH}$ condition, hydrolysis reaction is facilitated and condensation reaction is delayed [17].

Furthermore, it has been also reported that, under acidic conditions, positive charge of OR group partially increased to accelerate the hydrolysis reaction because $\mathrm{OH}$ group can easily attach on the surface of titanium ions in accordance with increasing repulsive force between positive charge of titanium ion and the OR group [17, 43, 44]. Consistent with the previous studies, our results also suggest that, under the low $\mathrm{pH}$ condition, the interaction between hydrogen and oxygen actively occurred during hydrolysis reaction, leading to the formation of water molecules adsorbed on the surface of the $\mathrm{TiO}_{2}$ powder, and accordingly, the increasing concentration of hydroxyl group and water molecules on the surface of $\mathrm{TiO}_{2}$. Therefore, the FT-IR (Figure 7) and methylene blue degradation experimental results (Figure 5 and Table 1) implied that photocatalytic activity of $\mathrm{TiO}_{2}$ nanoparticles was enhanced under low synthesis $\mathrm{pH}$ conditions due to the presence of abundant hydroxyl groups and water molecules existing on the surface of $\mathrm{TiO}_{2}$. Yu et al. [33] also observed the similar trend which was attributed to the improved acidity (i.e., the number of surface acid sites) of the samples synthesized at acidic $\mathrm{pH}$ conditions $\mathrm{pH}$.

\subsection{Effect of Calcination Temperature on Photocatalytic Activi-} ty of $\mathrm{TiO}_{2}$. Figure 8 and Table 1 show methylene blue degradation efficiency by $\mathrm{TiO}_{2}$ nanoparticles synthesized at $\mathrm{pH} 7$ with a $5 \mathrm{~mol}$ addition of water (i.e., molar ratio of water and TTIP $=5$ ) according to different calcination temperatures.

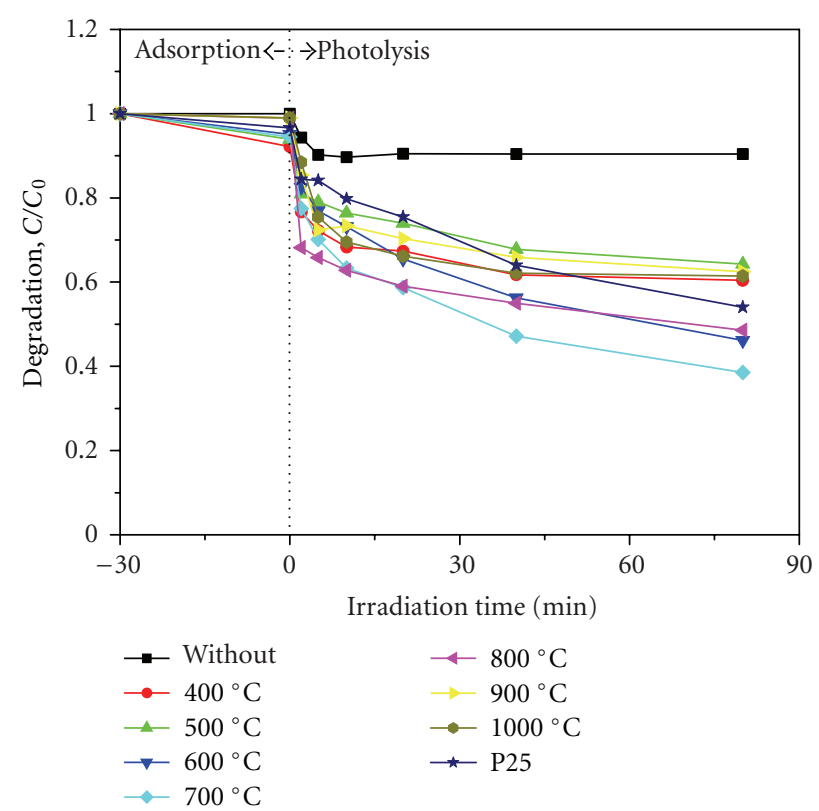

Figure 8: Photocatalytic degradation of methylene blue by $\mathrm{TiO}_{2}$ nanoparticles synthesized with different calcination temperatures. The $\mathrm{TiO}_{2}$ synthesis was carried out with a molar ratio (water and TTIP) of 5 and $\mathrm{pH}$ 7. The results from the experiments with P25 and noncalcined $\mathrm{TiO}_{2}$ and without $\mathrm{TiO}_{2}$ nanoparticles were also presented for comparison purpose.

For the reactors without $\mathrm{TiO}_{2}$ particles, no degradation was observed above $5 \mathrm{~min}$ after UV irradiation. On the other hand, all calcined $\mathrm{TiO}_{2}$ samples showed continuous methylene blue degradation. The efficiency increased up to $700^{\circ} \mathrm{C}$ (e.g., $k=0.871 \mathrm{~h}^{-1}$ for the sample calcined at $700^{\circ} \mathrm{C}$ ) but decreased with calcination temperature above that point $\left(k<0.871 \mathrm{~h}^{-1}\right.$ when calcination temperature $\left.>700^{\circ} \mathrm{C}\right)$. A similar trend was also observed from several previous studies [45-47]. Additionally, the sample calcined at $1000^{\circ} \mathrm{C}$ only exhibited photocatalytic activity up to $20 \mathrm{~min}$, and even after about $80 \mathrm{~min}$ the degree of activity was almost identical with that of the samples calcined at $500^{\circ} \mathrm{C}$ or below (Figure 8). The trend is likely due to relatively short reaction time (i.e., ca. $90 \mathrm{~min}$ ) investigated in this study, which may not be enough to see the distinct difference between both samples (Figure 8) [24, 48, 49]. Another plausible explanation could be the combined effect of the degree of crystallinity which was improved with increasing temperature and the specific surface area which decreased with increasing calcination temperature (Table 4).

In order to understand the trend for the methylene blue degradation efficiency by $\mathrm{TiO}_{2}$ nanoparticles with different calcination temperatures, crystalline structure and crystallite size of $\mathrm{TiO}_{2}$ nanoparticles were investigated. Figure 9 and Table 4 show XRD patterns for $\mathrm{TiO}_{2}$ nanoparticles calcined at different temperatures. Anatase peak started to appear at $400^{\circ} \mathrm{C}$ and increased up to $700^{\circ} \mathrm{C}$. Rutile phase started to appear at $700^{\circ} \mathrm{C}$, and the intensity increased from that point with almost no anatase phase at $900^{\circ} \mathrm{C}$ (i.e., anatase phase content $=\sim 3.7$ at $900^{\circ} \mathrm{C}$ ) (Table 4$)$. It was also observed 
TABle 4: Physicochemical properties of the $\mathrm{TiO}_{2}$ nanoparticles synthesized with different calcination temperatures. The TiO ${ }_{2}$ synthesis was carried out with a molar ratio (water and TTIP) of 5 and $\mathrm{pH} 7$.

\begin{tabular}{|c|c|c|c|c|}
\hline Temperature $\left({ }^{\circ} \mathrm{C}\right)$ & Phase content $^{\mathrm{a}}$ & $S_{\mathrm{BET}}^{\mathrm{b}}\left(\mathrm{m}^{2} \mathrm{~g}^{-1}\right)$ & Pore volume ${ }^{\mathrm{b}}\left(\mathrm{mm}^{3} \mathrm{~g}^{-1}\right)$ & Crystalline size $^{\mathrm{c}}(\mathrm{nm})$ \\
\hline 400 & (A): 100 & 83.3 & 85 & 9.6 \\
\hline 500 & (A): 100 & 40.1 & 55 & 13.7 \\
\hline 600 & (A): 100 & 38.2 & 69 & 18.0 \\
\hline \multirow[t]{2}{*}{700} & (A): 92.4 & 33.1 & 46 & $(\mathrm{~A}): 28.5$ \\
\hline & (R): 7.6 & & & (R): 33.1 \\
\hline \multirow[t]{2}{*}{800} & (A): 15.1 & 22.3 & 32 & (A): 58.9 \\
\hline & (R): 84.9 & & & (R): 94.1 \\
\hline \multirow[t]{2}{*}{900} & $(\mathrm{~A}): 3.7$ & 19.5 & 30 & (A): 77.2 \\
\hline & (R): 96.3 & & & $(\mathrm{R}): 113$ \\
\hline 1000 & (R): 100 & 16.1 & 26 & 138 \\
\hline
\end{tabular}

${ }^{\mathrm{a}} \mathrm{A}$ and $\mathrm{R}$ represent anatase and rutile, respectively.

${ }^{\mathrm{b}}$ Value calculated from nitrogen adsorption isotherm.

${ }^{\mathrm{c}}$ Value calculated using the Scherrer's equation [22].

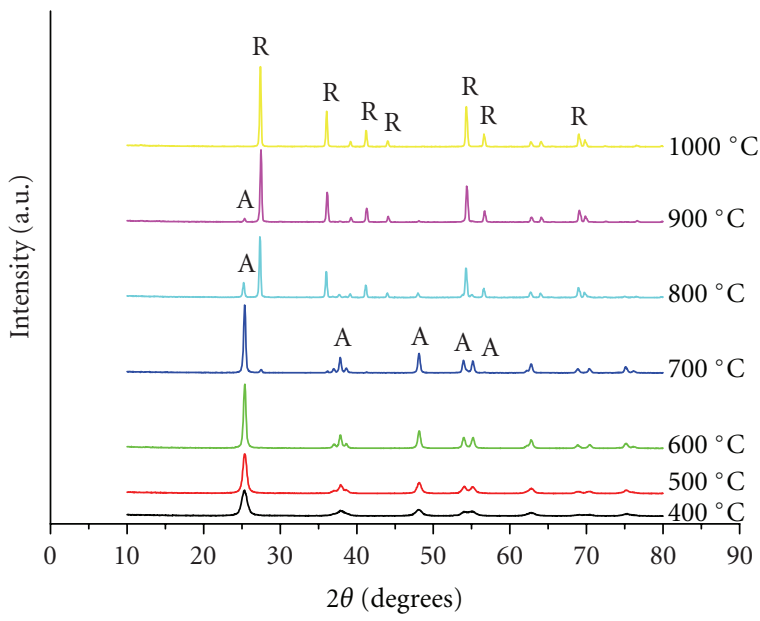

FIgURE 9: XRD patterns of $\mathrm{TiO}_{2}$ nanoparticles synthesized with different calcination temperatures. The $\mathrm{TiO}_{2}$ synthesis was carried out with a molar ratio (water and TTIP) of 5 and $\mathrm{pH}$ 7. A and $\mathrm{R}$ represent anatase and rutile, respectively.

that anatase phase was totally disappeared and transformed to rutile phase at $1000^{\circ} \mathrm{C}$. This result is consistent with a previous study which reported that $\mathrm{TiO}_{2}$ synthesized via a common sol-gel process showed phase transition at around $600^{\circ} \mathrm{C}$ or higher temperature [15]. Crystallite size of $\mathrm{TiO}_{2}$ particles with different calcination temperatures is also presented in Table 4. Overall, crystallite size increased with increasing calcination temperature, showing substantial increase at the temperature range between 700 and $800^{\circ} \mathrm{C}$. More specifically, the anatase crystallite size of the samples calcined at 700 and $800^{\circ} \mathrm{C}$ was determined to be 28.5 and $58.9 \mathrm{~nm}$, respectively (Table 4 ). These results suggest that crystallite size and phase transition were much more influenced by calcination temperature as compared to the amount of water addition (i.e., molar ratio of water and TTIP) and $\mathrm{pH}$ among the variables adjusted in the process of $\mathrm{TiO}_{2}$ synthesis investigated herein.

Specific surface area and pore volume of $\mathrm{TiO}_{2}$ particles synthesized at different calcination temperatures are listed in Table 4. Specific surface area and pore volume of the sample with lowest calcination temperature (i.e., $400^{\circ} \mathrm{C}$ ) were determined to be $83.3 \mathrm{~m}^{2} \mathrm{~g}^{-1}$ and $85 \mathrm{~mm}^{3} \mathrm{~g}^{-1}$, respectively. However, both specific surface area and pore volume gradually decreased with increasing calcination temperature, and the sample calcined at $1000^{\circ} \mathrm{C}$ showed the lowest values $\left(S_{\mathrm{BET}}=16.1 \mathrm{~m}^{2} \mathrm{~g}^{-1}\right.$ and pore volume $\left.=26 \mathrm{~mm}^{3} \mathrm{~g}^{-1}\right)$. These results are consistent with the finding from the previous study which reported the inverse relationship between crystallite size and specific surface area [23]. If specific surface area and pore volume of $\mathrm{TiO}_{2}$ nanoparticles were dominant factors controlling the photocatalytic activity of $\mathrm{TiO}_{2}$, the activity would have decreased with calcination temperature; however, the activity showed the maximum value at $700^{\circ} \mathrm{C}$. The trend is likely attributed to the combined effect of anatase crystallinity which showed the highest intensity at $700^{\circ} \mathrm{C}$ (Figure 9) [13] and crystallite size which did not excessively increase up to $700^{\circ} \mathrm{C}$ (Table 4). Furthermore, the decreasing photocatalytic activity for the samples with a calcination temperature of $800^{\circ} \mathrm{C}$ or above could be explained by the decreased specific surface area and the subsequent reduction in the adsorption sites for the degradation reaction due to the decrease in anatase crystallinity and the excessive growth in crystallite size [31, 32].

\section{Conclusions}

In the present study, the degradation behavior of methylene blue by $\mathrm{TiO}_{2}$ nanoparticles, which were synthesized under different synthesis conditions (i.e., molar ratio of water and TTIP, $\mathrm{pH}$, and calcination temperature) in a sol-gel process, was investigated. The correlation between physical properties and photocatalytic activity of $\mathrm{TiO}_{2}$ nanoparticles according to the different synthesis conditions is as follows.

(i) The amount of water added (i.e., molar ratio of water and TTIP), which was used as hydrolysis reagent, did not significantly influence the change in the crystallite size of $\mathrm{TiO}_{2}$ nanoparticles; however, anatase 
crystallinity slightly decreased for the $\mathrm{TiO}_{2}$ synthesized with large molar ratio of water and TTIP (i.e., 50). The increasing molar ratio led to the enhanced photocatalytic activity of $\mathrm{TiO}_{2}$ nanoparticles. The results were likely attributed to the increased specific surface area of $\mathrm{TiO}_{2}$ nanoparticles synthesized with high molar ratio, which resulted from the relative increase in the size of the inter-aggregated pores of aggregated $\mathrm{TiO}_{2}$ nanoparticles.

(ii) $\mathrm{TiO}_{2}$ nanoparticles synthesized at acidic conditions (i.e., $\mathrm{pH} 2$ and 4) showed the best photocatalytic activity. However, the results were not explained by the physical properties for the crystallinity and the crystallite size of $\mathrm{TiO}_{2}$ nanoparticles but explained by the extent of active surface functional groups (e.g., hydroxyl group). Specifically, under low $\mathrm{pH}$ conditions, photocatalytic activity of $\mathrm{TiO}_{2}$ nanoparticles was enhanced by the presence of abundant hydroxyl groups and water molecules existing on the surface of $\mathrm{TiO}_{2}$.

(iii) Methylene blue degradation experiments revealed that the photocatalytic activity of $\mathrm{TiO}_{2}$ nanoparticles was maximized at the calcination temperature of $700^{\circ} \mathrm{C}$. However, specific surface area and pore volume of $\mathrm{TiO}_{2}$ nanoparticles gradually decreased with increasing calcination temperature, indicating that those physical properties were not critical for controlling the photocatalytic activity of $\mathrm{TiO}_{2}$ nanoparticles. The trend was likely due to the combined effect of the anatase crystallinity which showed the highest value at $700^{\circ} \mathrm{C}$ and the crystallite size which did not excessively increase up to $700^{\circ} \mathrm{C}$.

The findings from this study indicate that physical properties of $\mathrm{TiO}_{2}$ nanoparticles, which played an important role on photocatalytic activity of $\mathrm{TiO}_{2}$, can be controlled by varying the synthesis conditions, such as amount of water addition (i.e., molar ratio of water and TTIP), $\mathrm{pH}$, and calcination temperature.

\section{Acknowledgments}

This paper was supported by the Basic Research Project (12530290) of the Korea Institute of Geoscience and Mineral Resources (KIGAM) and funded by the Ministry of Knowledge Economy of Korea.

\section{References}

[1] S. Boujday, F. Wünsch, P. Portes, J.-F. Bocquet, and C. C. Justin, "Photocatalytic and electronic properties of $\mathrm{TiO}_{2}$ powders elaborated by sol-gel route and supercritical drying," Solar Energy Materials and Solar Cells, vol. 83, no. 4, pp. 421-433, 2004.

[2] H. Chen, C. Su, J. Chen, T. Yang, N. Hsu, and W. Li, "Preparation and characterization of pure rutile $\mathrm{TiO}_{2}$ nanoparticles for photocatalytic study and thin films for dye-sensitized solar cells," Journal of Nanomaterials, vol. 2011, Article ID 869618, 8 pages, 2011.
[3] O. Legrini, E. Oliveros, and A. M. Braun, "Photochemical processes for water treatment," Chemical Reviews, vol. 93, no. 2, pp. 671-698, 1993.

[4] M. Srinivasan and T. White, "Degradation of methylene blue by three-dimensionally ordered macroporous titania," Environmental Science and Technology, vol. 41, no. 12, pp. 44054409, 2007.

[5] Q. Zhang, L. Gao, and J. Guo, "Effects of calcination on the photocatalytic properties of nanosized $\mathrm{TiO}_{2}$ powders prepared by $\mathrm{TiCl}_{4}$ hydrolysis," Applied Catalysis B, vol. 26, no. 3, pp. 207-215, 2000.

[6] J. Sin, S. Lam, A. R. Mohamed, and K. Lee, "Degrading endocrine disrupting chemicals from wastewater by $\mathrm{TiO}_{2}$ photocatalysis: a review," International Journal of Photoenergy, vol. 2012, Article ID 185159, 23 pages, 2012.

[7] M. I. Litter, "Heterogeneous photocatalysis: transition metal ions in photocatalytic systems," Applied Catalysis B, vol. 23, no. 2-3, pp. 89-114, 1999.

[8] W. Li, C. Liu, Y. Zhou et al., "Enhanced photocatalytic activity in anatase $/ \mathrm{TiO}_{2}$ (B) core-shell nanofiber," Journal of Physical Chemistry C, vol. 112, no. 51, pp. 20539-20545, 2008.

[9] S. Liu, J. Yu, and M. Jaroniec, "Anatase $\mathrm{TiO}_{2}$ with dominant high-energy 001 facets: synthesis, properties, and applications," Chemistry of Materials, vol. 23, no. 18, pp. 4085-4093, 2011.

[10] S. Liu, J. Yu, and M. Jaroniec, "Tunable photocatalytic selectivity of hollow $\mathrm{TiO}_{2}$ microspheres composed of anatase polyhedra with exposed 001 facets," Journal of the American Chemical Society, vol. 132, no. 34, pp. 11914-11916, 2010.

[11] J. Yu, H. Yu, B. Cheng, M. Zhou, and X. Zhao, "Enhanced photocatalytic activity of $\mathrm{TiO}_{2}$ powder (P25) by hydrothermal treatment," Journal of Molecular Catalysis A, vol. 253, no. 1-2, pp. 112-118, 2006.

[12] A. Fujishima, T. N. Rao, and D. A. Tryk, "Titanium dioxide photocatalysis," Journal of Photochemistry and Photobiology C, vol. 1, no. 1, pp. 1-21, 2000.

[13] G. Tian, H. Fu, L. Jing, and C. Tian, "Synthesis and photocatalytic activity of stable nanocrystalline $\mathrm{TiO}_{2}$ with high crystallinity and large surface area," Journal of Hazardous Materials, vol. 161, no. 2-3, pp. 1122-1130, 2009.

[14] B. B. Lakshmi, C. J. Patrissi, and C. R. Martin, "Sol-gel template synthesis of semiconductor oxide micro- and nanostructures," Chemistry of Materials, vol. 9, no. 11, pp. 25442550, 1997.

[15] J. Zhang, M. Li, Z. Feng, J. Chen, and C. Li, "UV raman spectroscopic study on $\mathrm{TiO}_{2}$. I. Phase transformation at the surface and in the bulk," The Journal of Physical Chemistry B, vol. 110, no. 2, pp. 927-935, 2006.

[16] T. Cao, Y. Li, C. Wang, C. Shao, and Y. Liu, "One-step nonaqueous synthesis of pure phase $\mathrm{TiO}_{2}$ nanocrystals from $\mathrm{TiCl}_{4}$ in butanol and their photocatalytic properties," Journal of Nanomaterials, vol. 2011, Article ID 267415, 6 pages, 2011.

[17] J. P. Nikkanen, T. Kanerva, and T. Mäntylä, "The effect of acidity in low-temperature synthesis of titanium dioxide," Journal of Crystal Growth, vol. 304, no. 1, pp. 179-183, 2007.

[18] M. N. Chong, B. Jin, C. W. K. Chow, and C. Saint, "Recent developments in photocatalytic water treatment technology: a review," Water Research, vol. 44, no. 10, pp. 2997-3027, 2010.

[19] U. I. Gaya and A. H. Abdullah, "Heterogeneous photocatalytic degradation of organic contaminants over titanium dioxide: a review of fundamentals, progress and problems," Journal of Photochemistry and Photobiology C, vol. 9, no. 1, pp. 1-12, 2008. 
[20] J. Yu, G. Wang, B. Cheng, and M. Zhou, "Effects of hydrothermal temperature and time on the photocatalytic activity and microstructures of bimodal mesoporous $\mathrm{TiO}_{2}$ powders," Applied Catalysis B, vol. 69, no. 3-4, pp. 171-180, 2007.

[21] Y. Li, X. Li, J. Li, and J. Yin, "Photocatalytic degradation of methyl orange by $\mathrm{TiO}_{2}$-coated activated carbon and kinetic study," Water Research, vol. 40, no. 6, pp. 1119-1126, 2006.

[22] D. S. Kim, S. J. Han, and S. Y. Kwak, "Synthesis and photocatalytic activity of mesoporous $\mathrm{TiO}_{2}$ with the surface area, crystallite size, and pore size," Journal of Colloid and Interface Science, vol. 316, no. 1, pp. 85-91, 2007.

[23] G. Oskam, A. Nellore, R. L. Penn, and P. C. Searson, "The growth kinetics of $\mathrm{TiO}_{2}$ nanoparticles from titanium(IV) alkoxide at high water/titanium ratio," Journal of Physical Chemistry B, vol. 107, no. 8, pp. 1734-1738, 2003.

[24] H. Kim, S. Lee, Y. Han, and J. Park, "Preparation of dipcoated $\mathrm{TiO}_{2}$ photocatalyst on ceramic foam pellets," Journal of Materials Science, vol. 41, no. 18, pp. 6150-6153, 2006.

[25] S. Brunauer, P. H. Emmett, and E. Teller, "Adsorption of gases in multimolecular layers," Journal of the American Chemical Society, vol. 60, no. 2, pp. 309-319, 1938.

[26] J. Yu, S. Liu, and H. Yu, "Microstructures and photoactivity of mesoporous anatase hollow microspheres fabricated by fluoride-mediated self-transformation," Journal of Catalysis, vol. 249, no. 1, pp. 59-66, 2007.

[27] E. P. Barrett, L. G. Joyner, and P. P. Halenda, "The determination of pore volume and area distributions in porous substances. I. Computations from nitrogen isotherms," Journal of the American Chemical Society, vol. 73, no. 1, pp. 373-380, 1951.

[28] J. Yu, J. C. Yu, M. K. P. Leung et al., "Effects of acidic and basic hydrolysis catalysts on the photocatalytic activity and microstructures of bimodal mesoporous titania," Journal of Catalysis, vol. 217, no. 1, pp. 69-78, 2003.

[29] B. Li, X. Wang, M. Yan, and L. Li, "Preparation and characterization of nano- $\mathrm{TiO}_{2}$ powder," Materials Chemistry and Physics, vol. 78, no. 1, pp. 184-188, 2002.

[30] Y. Li, N. H. Lee, E. G. Lee, J. S. Song, and S. J. Kim, “The characterization and photocatalytic properties of mesoporous rutile $\mathrm{TiO}_{2}$ powder synthesized through self-assembly of nano crystals," Chemical Physics Letters, vol. 389, no. 1-3, pp. 124$128,2004$.

[31] R. Tan, Y. He, Y. Zhu, B. Xu, and L. Cao, "Hydrothermal preparation of mesoporous $\mathrm{TiO}_{2}$ powder from $\mathrm{Ti}\left(\mathrm{So}_{4}\right)_{2}$ with poly(ethylene glycol) as template," Journal of Materials Science, vol. 38, no. 19, pp. 3973-3978, 2003.

[32] T. Peng, D. Zhao, K. Dai, W. Shi, and K. Hirao, "Synthesis of titanium dioxide nanoparticles with mesoporous anatase wall and high photocatalytic activity," Journal of Physical Chemistry B, vol. 109, no. 11, pp. 4947-4952, 2005.

[33] J. Yu, Y. Su, B. Cheng, and M. Zhou, "Effects of pH on the microstructures and photocatalytic activity of mesoporous nanocrystalline titania powders prepared via hydrothermal method," Journal of Molecular Catalysis A, vol. 258, no. 1-2, pp. 104-112, 2006.

[34] S. Mahshid, M. Askari, and M. S. Ghamsari, "Synthesis of $\mathrm{TiO}_{2}$ nanoparticles by hydrolysis and peptization of titanium isopropoxide solution," Journal of Materials Processing Technology, vol. 189, no. 1-3, pp. 296-300, 2007.

[35] V. Puddu, H. Choi, D. D. Dionysiou, and G. L. Puma, " $\mathrm{TiO}_{2}$ photocatalyst for indoor air remediation: influence of crystallinity, crystal phase, and UV radiation intensity on trichloroethylene degradation," Applied Catalysis B, vol. 94, no. 3-4, pp. 211-218, 2010.
[36] X. Y. Chuan, M. Hirano, and M. Inagaki, "Preparation and photocatalytic performance of anatase-mounted natural porous silica, pumice, by hydrolysis under hydrothermal conditions," Applied Catalysis B, vol. 51, no. 4, pp. 255-260, 2004.

[37] Y. V. Kolen'ko, B. R. Churagulov, M. Kunst, L. Mazerolles, and C. Colbeau-Justin, "Photocatalytic properties of titania powders prepared by hydrothermal method," Applied Catalysis $B$, vol. 54, no. 1 , pp. 51-58, 2004.

[38] A. Sclafani, L. Palmisano, and M. Schiavello, "Influence of the preparation methods of titanium dioxide on the photocatalytic degradation of phenol in aqueous dispersion," The Journal of Physical Chemistry, vol. 94, no. 2, pp. 829-835, 1990.

[39] S. J. Kim, H. G. Lee, S. J. Kim, J. K. Lee, and E. G. Lee, "Photoredox properties of ultrafine rutile $\mathrm{TiO}_{2}$ acicular powder in aqueous 4-chlorophenol, Cu-EDTA and Pb-EDTA solutions," Applied Catalysis A, vol. 242, no. 1, pp. 89-99, 2003.

[40] X. Zhang, F. Zhang, and K. Y. Chan, "Synthesis of titaniasilica mixed oxide mesoporous materials, characterization and photocatalytic properties," Applied Catalysis A, vol. 284, no. 12, pp. 193-198, 2005.

[41] Z. Ding, G. Q. Lu, and P. F. Greenfield, "Role of the crystallite phase of $\mathrm{TiO}_{2}$ in heterogeneous photocatalysis for phenol oxidation in water," Journal of Physical Chemistry B, vol. 104, no. 19, pp. 4815-4820, 2000.

[42] L. Q. Jing, H. G. Fu, B. Q. Wang et al., "Effects of Sn dopant on the photoinduced charge property and photocatalytic activity of $\mathrm{TiO}_{2}$ nanoparticles," Applied Catalysis B, vol. 62, no. 3-4, pp. 282-291, 2006.

[43] M. Gopal, W. J. Moberly Chan, and L. C. De Jonghe, "Room temperature synthesis of crystalline metal oxides," Journal of Materials Science, vol. 32, no. 22, pp. 6001-6008, 1997.

[44] P. Bonamali, S. Maheshwar, and N. Gyoichi, "Preparation and characterization of $\mathrm{TiO}_{2} / \mathrm{Fe}_{2} \mathrm{O}_{3}$ binary mixed oxides and its photocatalytic properties," Materials Chemistry and Physics, vol. 59, no. 3, pp. 254-261, 1999.

[45] K. Lv, Q. Xiang, and J. Yu, "Effect of calcination temperature on morphology and photocatalytic activity of anatase $\mathrm{TiO}_{2}$ nanosheets with exposed 001 facets," Applied Catalysis B, vol. 104, no. 3-4, pp. 275-281, 2011.

[46] J. Yu and B. Wang, "Effect of calcination temperature on morphology and photoelectrochemical properties of anodized titanium dioxide nanotube arrays," Applied Catalysis B, vol. 94, no. 3-4, pp. 295-302, 2010.

[47] J. G. Yu, H. G. Yu, B. Cheng, X. J. Zhao, J. C. Yu, and W. K. Ho, "The effect of calcination temperature on the surface microstructure and photocatalytic activity of $\mathrm{TiO}_{2}$ thin films prepared by liquid phase deposition," Journal of Physical Chemistry B, vol. 107, no. 50, pp. 13871-13879, 2003.

[48] C. Wen, Y. J. Zhu, T. Kanbara, H. Z. Zhu, and C. F. Xiao, "Effects of I and $\mathrm{F}$ codoped $\mathrm{TiO}_{2}$ on the photocatalytic degradation of methylene blue," Desalination, vol. 249, no. 2, pp. 621$625,2009$.

[49] H. Le, L. Linh, S. Chin, and J. Jurng, "Photocatalytic degradation of methylene blue by a combination of $\mathrm{TiO}_{2}$-anatase and coconut shell activated carbon," Powder Technology, vol. 225, pp. 167-175, 2012. 

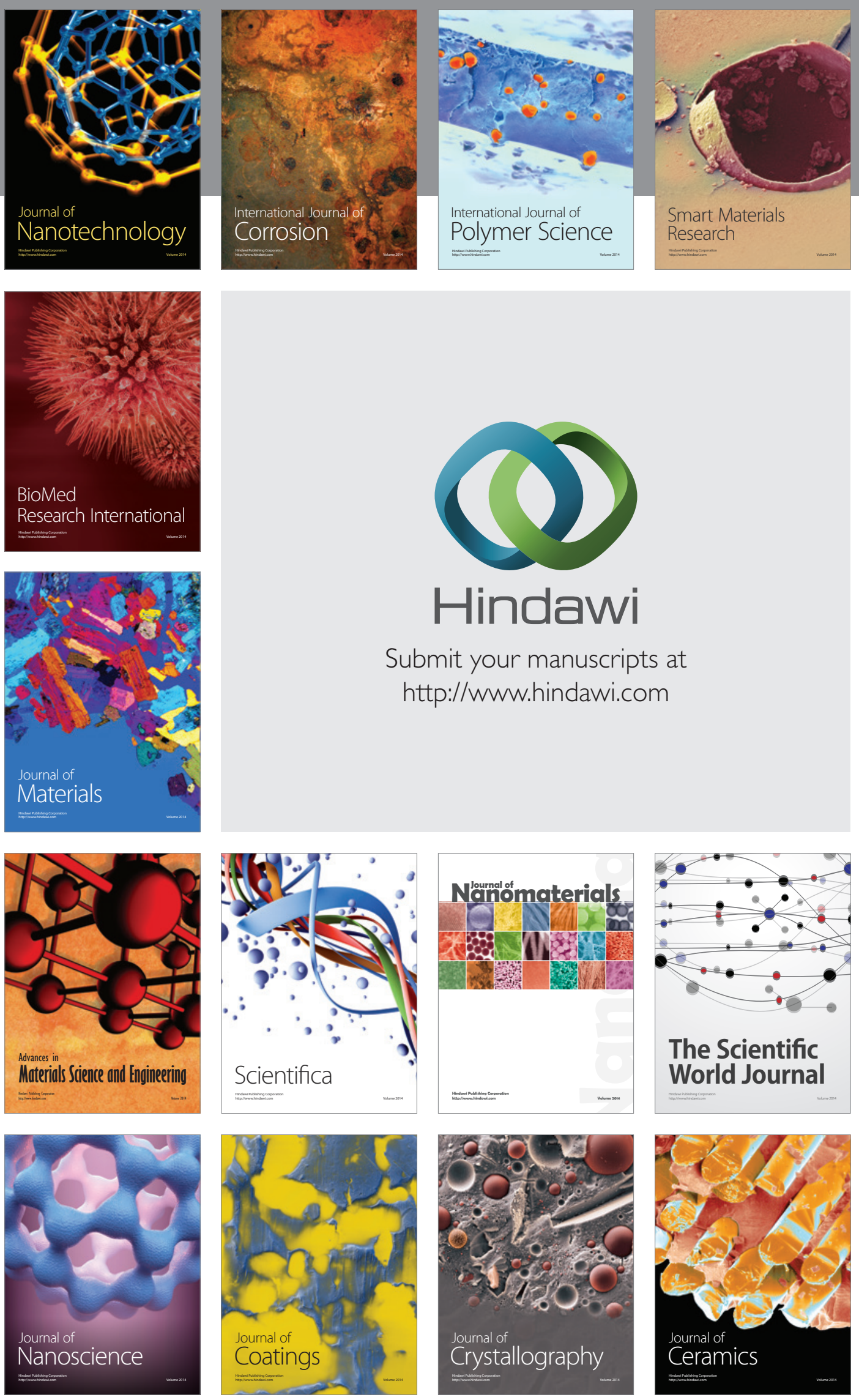

The Scientific World Journal

Submit your manuscripts at

http://www.hindawi.com

\section{World Journal}

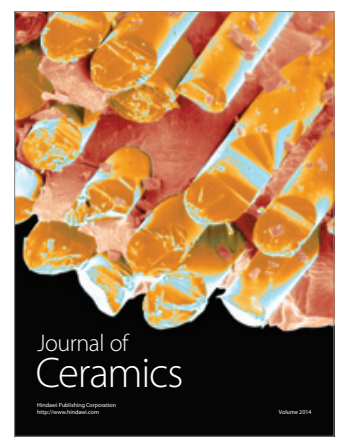

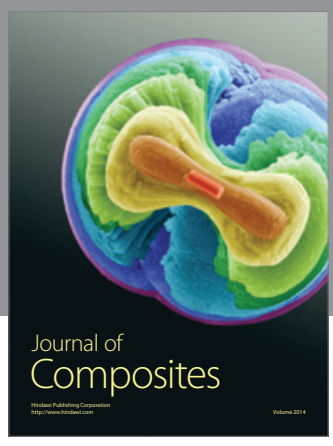
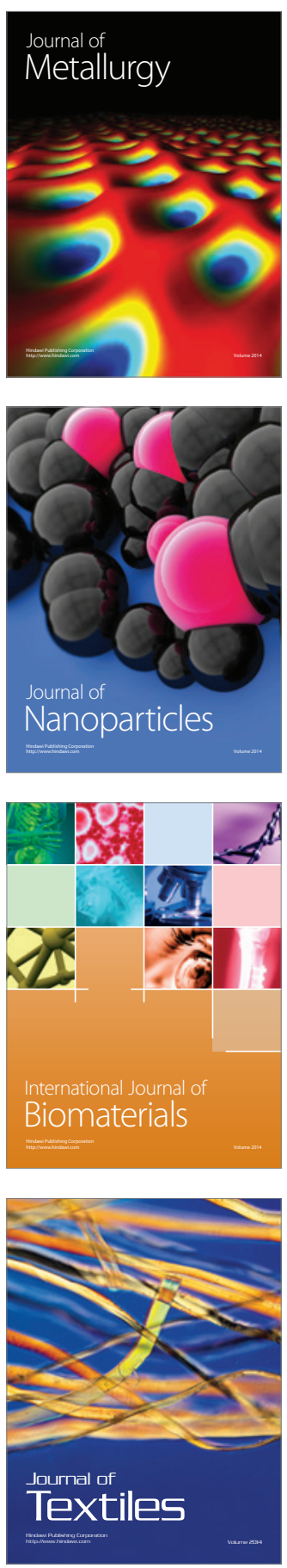